\title{
Brief/Short Communication: New Record of Culex Poicilipes from Saudi Arabia (Jazan Region)
}

\author{
E.M. Noureldin ${ }^{*}$, A.M. Sahli' ${ }^{2}$, O.M. Daffalla ${ }^{1}$, M.A. Jubran ${ }^{2}$, A.A. Alzhrani ${ }^{2}$, S.M Waheed ${ }^{1}$ \\ Y.A. Hobani ${ }^{1}$, R.M. Shajri ${ }^{2}$, and Z.M. Eisa ${ }^{1}$ \\ 1. Public Health Authority (Laboratories of vector-borne diseases), Saudi Arabia \\ 2. Department of vector-borne and zoonotic diseases, MOH - Jazan, Saudi Arabia
}

\begin{abstract}
This record represents the first report for adult Culex poicilipes from Saudi Arabia (a farm near Albahir village of Sabya Governate, Jazan region southwest of Saudi Arabia, N: 42.58810, E:17.121738) was noted. This was occurred during a routine surveillance for adult mosquitoes in February 2021 carried out by Sabya vector control station and the laboratory of vector-borne diseases, Saudi Public Health Authority. With this new record, the number of Culex mosquito species known to occur in Jazan region increases to 19 while for Saudi Arabia to 20. Similarly, the total number of mosquito species known to occur in Saudi Arabia increases to 50.This record necessitates conducting more researches on the biology and bionomics of Culex poicilipes under local conditions, as well as complementing the morphological identification with molecular characterizations and gene diversity. The possible role of the species in pathogens transmission, especially West Nile and Rift Valley fever viruses, should also be investigated.
\end{abstract}

Keywords: Culex poicilipes, New record, Saudi Arabia, Jazan region

DOI: $10.7176 / \mathrm{JEES} / 11-4-03$

Publication date: April $30^{\text {th }} 2021$

\section{Introduction}

Mosquito fauna of Saudi Arabia have been widely studied by many authors. These studies were summarized and updated in a list published by Alahmad et al., (2019) containing forty-nine mosquito species definitely known to occur in the country (18 Anophelines and 31 Culicines).

Mosquito-borne diseases in Saudi Arabia including dengue fever, malaria, Rift Valley fever and microfilariae, cause diseases in the KSA (Alhaeli et al., 2016; Samy et al., 2017; Hotez et al., 2012). Correct identification of vector species and knowledge of their distributions and biology in a specific geographical area are crucial requirements for disease epidemiology and control.

It is highly required to have adequate information about mosquito species and their geographical distribution in a certain area to determine the risk of relevant disease transmission.

In general, Culex mosquitoes are proven or suspected vectors of variety of Encephalitis, West Nile, and Rift Valley fever viruses, and Microfilariae (Michael, 2012; Irish et al., 2018). Similarly, Culex poicilipes is a known vector of West Nile and Rift Valley fever viruses in west Africa especially Senegal and Mauritania (Diallo et al., 2005). The aim of this brief communication is to record Culex poicilipes from Saudi Arabia for the time.

\section{Materials and Methods}

\subsection{Study Area:}

Jazan area is about $11670 \mathrm{~km} 2$, lies between $16^{\circ}-12$, and $18^{\circ}-25$, latitude north, and located in the subtropical zone, south-western of Saudi Arabia, with a coastal boundary of $250 \mathrm{~km}$ along the Red Sea and a $120 \mathrm{~km}$ border with the Republic of Yemen (Figure. 1). This region includes over 3000 villages scattered along the area, and about 100 islands located in the Red Sea, including the Farasan islands. It is surrounded by the Red Sea from the west and by Arabic Republic of Yemen from the south and east and Asir region from the north, with a total area of about 22,000 $\mathrm{km} 2$ and 1.6 million population [Alsheikh (2011); GASTAT 2017: https://www.stats.gov.sa/en/5655]. 


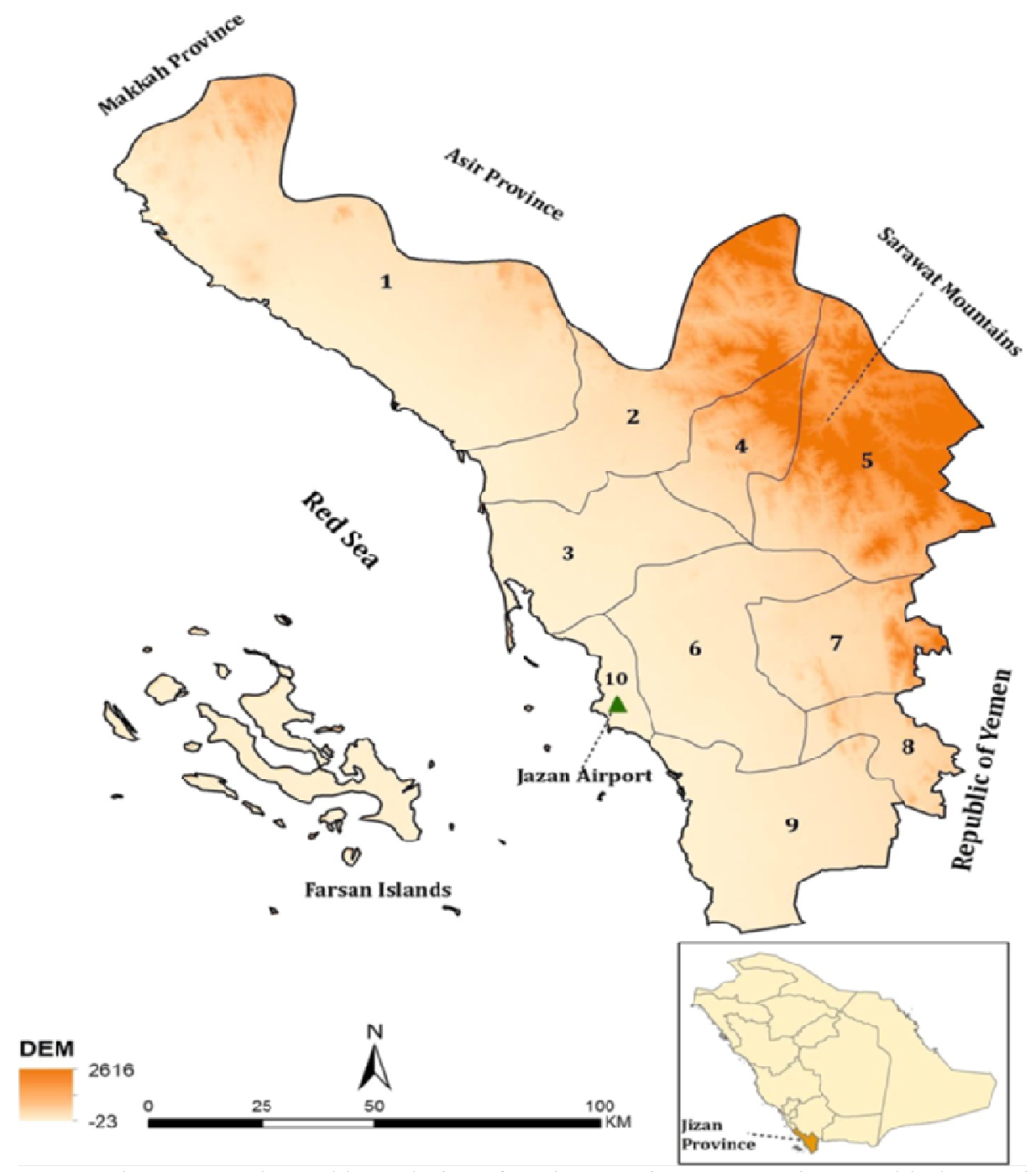

Figure 1. The topography and boundaries of study areas in Jazan Region; 1 Aldarb, 2 Baish,

3 Sabya, 4 Haroob, 5 Eleidabi (Eiban, Belgazzi), 6 Abuareesh, 7 Al-Ariddah, 8 Al-khoba, 9 Samttah, and 10 Jazan/ Farasan Islands.

\subsection{Collection and Identification of Mosquitoes}

Studied specimens of adult mosquito species were caught in the field using Blackhole light trap (BioTrap, Seoul, Korea, http://www.bio-trap.com) installed in a farm near Albahir village of Sabya Governate, Jazan region southwest of Saudi Arabia (N: $42.58810 \quad$ E:17.121738,). This was done during a routine surveillance of adult mosquitoes in February 2021 carried out by Sabya vector control station. Mosquito specimens were then brough to the Public Health Authority (laboratory of vector-borne diseases) for morphological identification. Pictorial keys by (Harbach, 1985), Glick (1992), and Azari-Hamidian \& Harbach (2009) were used in mosquito species identification.

\section{Results}

Identification of the adult mosquito species caught in the Blackhole light trap revealed the presence of 6 species belonging to 3 genera. These are: Anopheles arabiensis, Aedes aegypti, Culex tritaeniorhynchus, Culex pipens, Culex quinquefasciatus, and Culex poicilipes (Table 1). However, Culex poicilipes is identified for the first time from the Jazan region and the kingdom of Saudi Arabia.

Table 1. Identified mosquito species from a farm near Albahir village, Sabya - Jazan region.

\begin{tabular}{|c|c|c|c|c|c|c|c|}
\hline \multirow{2}{*}{ Area } & Coordinates & \multicolumn{6}{|c|}{ Identified mosquito species } \\
\cline { 3 - 8 } & $\begin{array}{l}\text { Anopheles } \\
\text { arabiensis }\end{array}$ & $\begin{array}{c}\text { Aedes } \\
\text { aegypti }\end{array}$ & $\begin{array}{c}\text { Culex } \\
\text { tritaeniorhynchus }\end{array}$ & $\begin{array}{c}\text { Culex } \\
\text { pipens }\end{array}$ & $\begin{array}{c}\text { Culex } \\
\text { quinquefasciatus }\end{array}$ & $\begin{array}{c}\text { Culex } \\
\text { poicilipes }\end{array}$ \\
\hline $\begin{array}{l}\text { Albahir } \\
\text { village }\end{array}$ & $\mathrm{N}: 42.58810$ & 3 & 2 & 36 & 7 & 5 & 8 \\
\hline
\end{tabular}


Using the pictorial key of Harbach (1985) and the website of Walter Reed Biosystematics Unit (WRBU) (Culex poicilipes (Theobald, 1903) $\mid$ Walter Reed Biosystematics Unit (WRBU) (si.edu)), the following morphological features were noted for Culex poicilipes from Saudi Arabia:

Head: Proboscis with median pale band, and it was longer than forefemur (Fig.2).

Thorax: Mesepimeral setae absent; Lower proepisternal scales present. Scutum without well-marked patterns (Fig.3)

Wings: Dark-scaled (Fig.4).

Legs: Anterior surfaces of femora and tibiae with rows of small pale spots, tarsus with narrow basal pale rings (Fig.5).

Abdomen: tergites with basal pale bands (Fig.4).

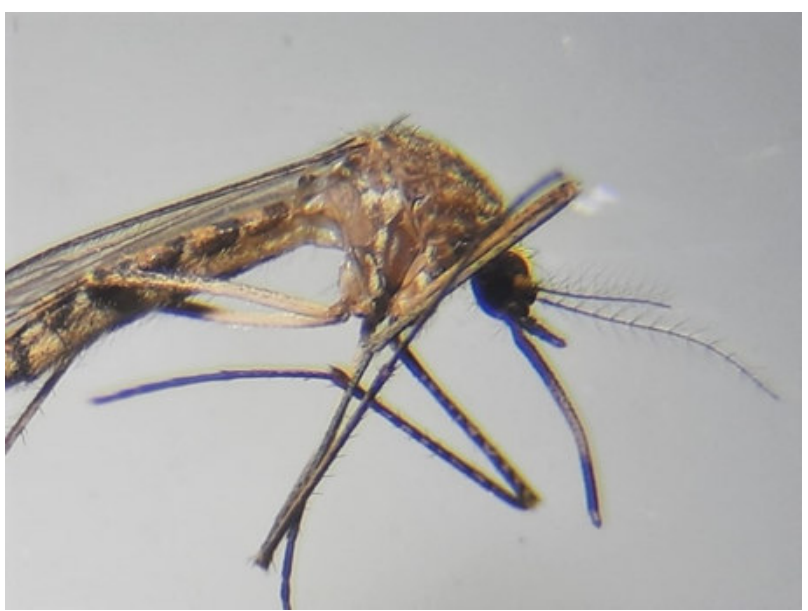

A

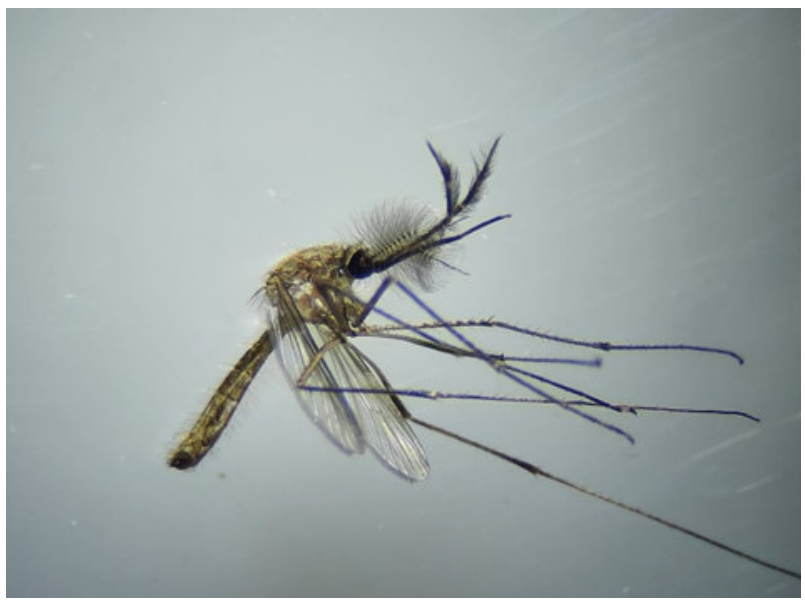

B

Figure 2. A: Proboscis of female Culex poicilipes with median pale band. B: Male

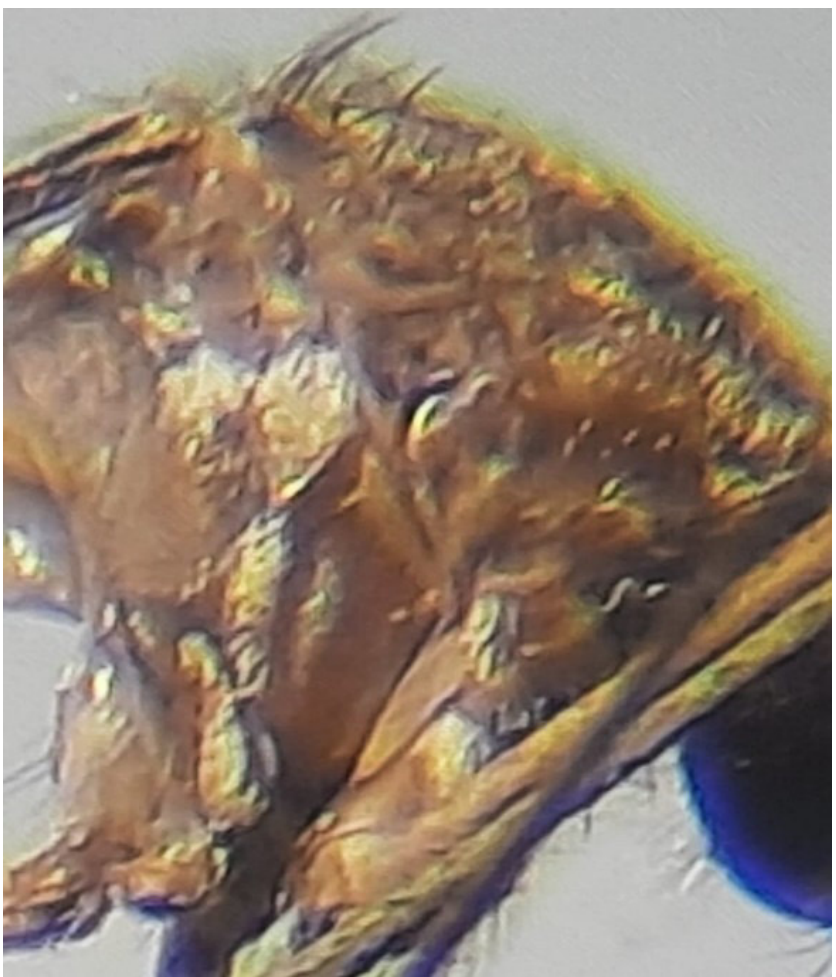

Figure 3. Mesepimeral setae absent; Lower proepisternal scales present. 


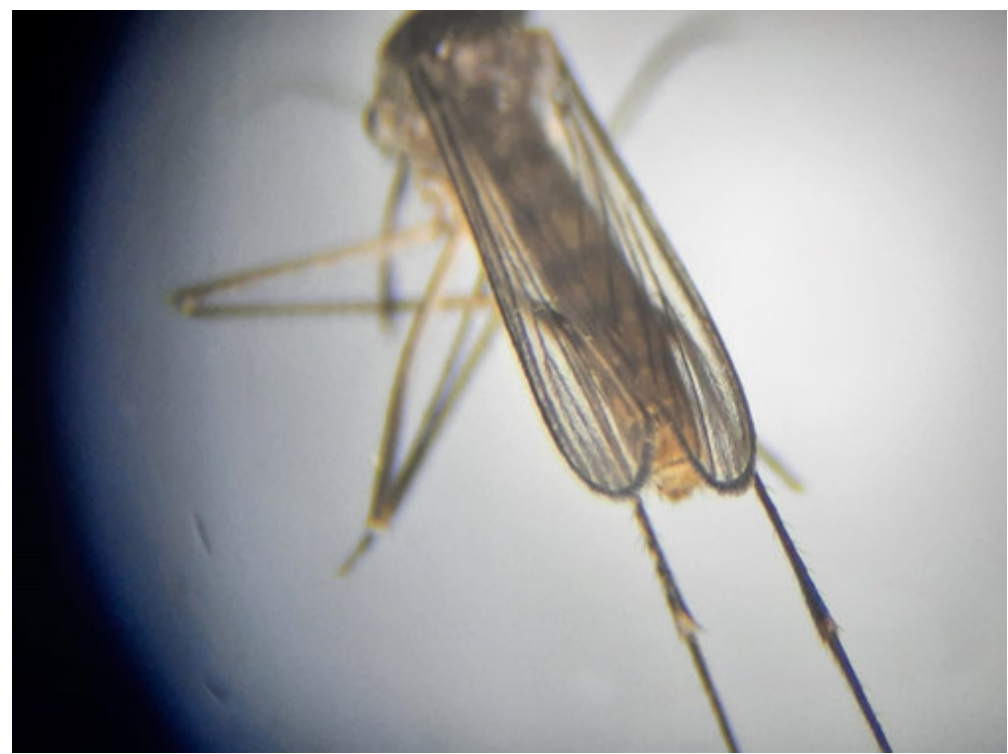

Figure 4. Wing dark-scaled, tergites with basal pale bands.
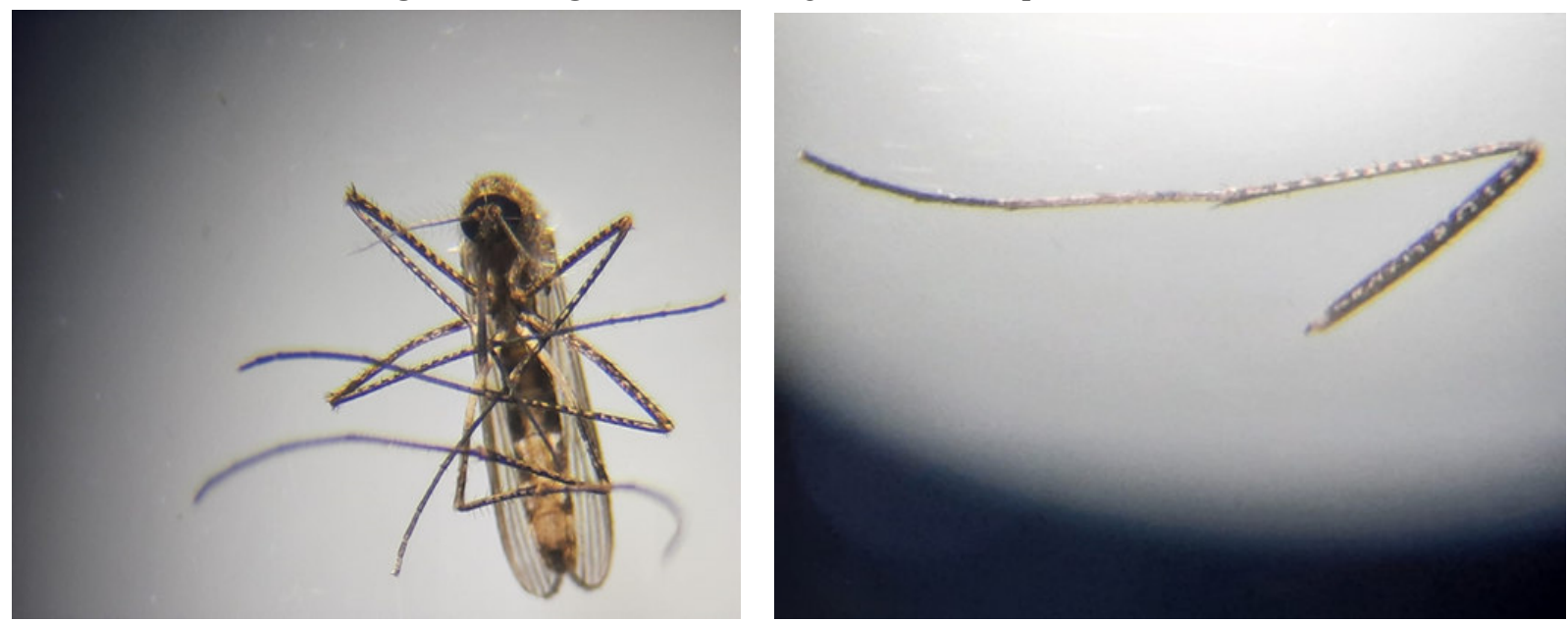

Figure 5. Anterior surfaces of femora and tibiae with rows of small pale spots, and tarsus with narrow basal pale rings.

\section{Discussion}

In this study, Cx. poicilipes species was recorded for the first time from southwest of Saudi Arabia, Sabya Governate. The other mosquito species identified in this study, namely; Anopheles arabiensis, Aedes aegypti, Culex tritaeniorhynchus, Culex pipens, and Culex quinquefasciatus (Table 1) are known potential vectors of diseases in the region and the kingdom; malaria, dengue, Rift Valley Fever, and lymphatic filariasis, respectively.

The adults of $C x$. poicilipes are dark, large mosquito species with attractive rows of speckled (pale spots) along its femora and tibiae. It has also a distinct median pale band on its proboscis (Figure 2) (WRBU, 2021).

The latest updated list of mosquito fauna and their distribution in Saudi Arabia revealed the presence of forty-nine mosquito species (18 Anophelines and 31 Culicines) belonging to seven genera. Of the 31 Culicines, 19 species were belonging to the genus Culex Linnaeus (1758), namely; Culex. pusillus, Cx. Nebulosus, Cx. Bitaeniorhynchus, Cx. Arbieeni, Cx. Salisburiensis, Cx. decens, Cx. duttoni, Cx. laticinctus, Cx. mattinglyi, Cx. mimeticus, $C x$. perexiguus, $C x$. pipiens, $C x$. quinquefasciatus, $C x$. simpsoni, Cx. sinaiticus, $C x$. sitiens, $C x$. theileri, Cx. tritaeniorhynchus, and Cx. univittatus (Alahmed et al., 2019).

Except for Cx. Nebulosus, the other 18 species of Culex have been reported from Jazan region (Alahmed et al., 2010; Alsheikh et al., 2013; Bakr et al., 2014; Harbach, 1985; Khater et al., 2013; Gaffigan et al., 2019; Alahmed et al., 2019).

Immature stages of $C x$. poicilipes were found in swamps, marshy depressions near rivers, clean fresh water sites, mature rice fields, and lakes with abundant floating vegetation. In Egypt, the bionomics studies revealed that the adult female of $C x$. poicilipes was found to be highly anthropophilic and enters houses to feed. while in 
South Africa, it could feed on arboreal fauna. $C x$. poicilipes is regarded as primarily ornithophilic In Kenya, whereas in Senegal its feeding habits are opportunistic and can feed on goats, sheep, cattle, chickens and mammals.

Furthermore, 36 strains of Rift Valley Fever virus (RVFV) were screened in Cx. poicilipes in Senegal, confirming its significant role in disease transmission (Culex poicilipes (Theobald, 1903) Walter Reed Biosystematics Unit (WRBU) (si.edu)); (WRBU, 2021).

The record of $C x$. poicilipes for the first time in Saudi Arabia necessitates conducting more researches on its biology and bionomics under local conditions, as well as complementing the morphological identification with molecular characterizations and gene diversity.

\section{Conclusion}

This study recorded Cx. poicilipes for the first time from Saudi Arabia, Jazan region. With this new record, the number of Culex mosquito species for Jazan region increases to 19 while for Saudi Arabia to 20. Similarly, the total number of mosquito species known to occur in Saudi Arabia increases to 50.

This finding should draw the attention of the vector surveillance and control programs in Jazan region to detect more adults and immature stages of $C x$. poicilipes from the region areas and study their possible role in pathogens transmission, in particular Rift Valley and West Nile viruses.

\section{Recommendations}

1. To complement this morphological identification of $C x$. poicilipes with its molecular characteristics.

2. To survey for immature stages of $C x$. poicilipes in Jazan region, especially Sabya Governate.

3. To explore the role of this species in pathogens transmission in Saudi Arabia especially RVF and West Nile viruses, as it is the main vector of RVF in west Africa (Senegal and Mauritania).

\section{References}

Alahmed Azzam M., Kashif Munawar, Sayed M. S. Khalil, and Ralph E. Harbach. (2019). “Assessment and an updated list of the mosquitoes of Saudi Arabia" Parasites Vectors, 12:356. https://doi.org/10.1186/s13071-019-3579-4.

Alahmed AM, Al Kuriji MA, Kheir SM, Al Haqawi HM, Sultan EAA. (2010). "Mosquito (Diptera: Culicidae) and their seasonal activity in Jazan Region, Saudi Arabia" J Saudi Soc Agric Sci, 9:136-138.

Alhaeli A, Bahkali S, Ali A, Househ MS, El-Metwally AA. (2016). The epidemiology of dengue fever in Saudi Arabia: a systematic review. J Infect Public Health. 9:117-24.

Alsheikh, A. A. (2011). Larval habitat, ecology, seasonal abundance and vectorial role in malaria transmission of Anopheles arabiensis in Jazan Region of Saudi Arabia. Egypt Soc. Parasitol. 41(3):615-34.

Alsheikh, A.A., Zafer M.H, Anaami A.G., Solan Y.M., Noureldin E.M., Mohammed W.S., Bakhait O.D., Sahli A. M., Alattas M.S., Alzahrani M.H., Alhakeem R.F., and Memish Z.A. (2013). "Potential mosquito vectors of arboviral diseases in Jazan Region, Saudi Arabia" Biosci. Biotech. Res. Comm, 6 (2) 142-149.

Bakr RFA, Nassar MI, El-Barky NM, Kotb TF, Badrawy H, Abdeldayem MS. (2014). "Prevalence of mosquitoes in Jazan Province, Saudi Arabia" Egypt. Acad J Biol Sci A Entomol, 7:15-27.

Diallo M, Nabeth P, Ba K, Sall AA, Ba Y, Mondo M, Girault L, Abdalahi MO, Mathiot C. (2005). Mosquito vectors of the 1998-1999 outbreak of Rift Valley Fever and other arboviruses (Bagaza, Sanar, Wesselsbron and West Nile) in Mauritania and Senegal. Med Vet Entomol. (2):119-26. doi: 10.1111/j.0269283X.2005.00564. x. PMID: 15958020.

Gaffigan TV, Wilkerson RC, Pecor JE, Stoffer JA, Anderson T. (2019) "Systematic catalog of Culicidae Suitland" Walter Reed Biosystematics Unit, Museum Support Center, Smithsonian Institution; http://www.mosquitocatalog.org/.

Glick, J.I. (1992). Illustrated key to the female Anopheles of Southwestern Asia and Egypt. Mosq. Syst. 24 (2), $125-153$.

Harbach RE. (1985). "Pictorial keys to the genera of mosquitoes, subgenera of Culex and the species of Culex (Culex) occurring in southwestern Asia and Egypt, with a note on the subgeneric placement of Culex deserticola (Diptera: Culicidae)" Mosq Syst, 17:83-107.

Hotez PJ, Savioli L, Fenwick A. (2012). Neglected tropical diseases of the Middle East and North Africa: review of their prevalence, distribution, and opportunities for control. PloS Negl Trop Dis. 6: e1475.

Irish SR, Al-Amin HM, Paulin HN, Mahmood ASMS, Khan RK, Muraduzzaman AKM, et al. (2018). "Molecular xenomonitoring for Wuchereria bancrofti in Culex quinquefasciatus in two districts in Bangladesh supports transmission assessment survey findings" PLoS Negl Trop Dis 12(7): e0006574, https://doi.org/10.1371/journal.pntd.0006574. 
Khater EI, Sowilem MM, Sallam MF, Alahmed AM. (2013). "Ecology and habitat characterization of mosquitoes in Saudi Arabia" Trop Biomed, 30: 409-427.

Michael J. Turell (2012). "Members of the Culex pipiens Complex as Vectors of Viruses," Journal of the American Mosquito Control Association 28(4s), 123-126, https://doi.org/10.2987/8756-971X-28.4.123.

Samy AM, Peterson AT, Hall M. (2017). Phylogeography of Rift Valley fever virus in Africa and the Arabian Peninsula. PLoS Negl Trop Dis. 11: e0005226.

Shahyad Azari-Hamidian \& Ralf E. Harbach (2009). Keys to the adult females and fourth-instar larvae of the mosquitoes of Iran (Diptera: Culicidae). Zootaxa 2078:1-33.

DOI: $10.5281 /$ zenodo. 187282

Walter Reed Biosystematics Unit (2021). Culex poicilipes species page. Walter Reed Biosystematics Unit Website, http://wrbu.si.edu/vectorspecies/mosquitoes/poicilipes. (Accessed 05 March 2021) 